\title{
Lei № 8.666/93 e PL № 559/13': as principais mudanças para o gestor público
}

\section{Daliana Bolzan Paz \\ Magali de Moraes Menti}

Universidade Estadual do Rio Grande do Sul, Especialização em Gestão Pública, Porto Alegre, RS, Brasil.

E-mails: eng.bolzan@gmail.com magali-menti@uergs.edu.br

Recebido em: 21 jun. 2017. Revisado: 01 nov. 2017. Aceito: 22 nov. 2017.

DOI: http://dx.doi.org/10.21674/2448-0479.42.198-217

\section{Resumo}

Tramita no Senado o projeto de Lei - PL no 559/13, o qual visa à substituição da atual Lei de Licitações - Lei no 8.666/93, junto com a Lei do Pregão - Lei no 10.520/02 e Regime Diferenciado de Contratações Públicas (RDC)- Lei no 12.462/11. É de fundamental importância para o gestor público conhecer as normas e leis referentes à licitação, para desempenhar de forma mais eficiente, ágil e com qualidade as suas funções. Este artigo tem como fim relatar uma pesquisa realizada no segundo semestre de 2015 cujo objetivo foi identificar as principais mudanças para o gestor público que ocorrerão com a mudança da Lei o 8.666/93 para o PL no 559/13, analisando os itens e descrevendo os principais pontos positivos e negativos, vantagens e desvantagens dessas alterações. Apresenta como referencial teórico o gestor público e a importância da licitação, a licitação pública, competência para legislar, principais avanços da legislação, Lei oㅜ 8.666/93 e suas modificações, PL no 559/13, Lei oㅜ 12.462/11 e Lei oㅜ 10.520/02. A pesquisa relatada compara a Lei oㅡ 8.666/93 e o PL no 559/13, identificando as principais mudanças apresentadas, de acordo com os autores e entidades representativas pesquisadas. Apresenta ao final 4 itens e 11 subitens de mudanças, dos quais foram consideradas 4 alterações como benéficas e 11 como desvantagens ou danosas para o gestor público e a Administração Pública. Identificou que a maioria das mudanças propostas apresenta pontos negativos. Conclui-se que a Lei de Licitações deve adequar-se e ser alterada após um profundo estudo e discussões com todas as entidades envolvidas, para embasarem com o devido amadurecimento e confiabilidade as alterações, suprindo a necessidade existente. A mera substituição de uma norma por outra ou sua repetição, não conduz ao aperfeiçoamento tão almejado, devendo-se buscar com essa alteração a transformação em um instrumento permanente.

Palavras-chave: Lei de Licitações. Lei oㅜ 12.462/11. Lei oํ 10.520/02.

\footnotetext{
${ }^{1}$ A pesquisa de que trata este artigo foi desenvolvida durante o ano de 2015 . Em fevereiro de 2017 foi aprovado o texto do PL 559/13 no Senado e encaminhado para Câmara dos Deputados como PL 6814/2017, onde atualmente encontrase aguardando criação de Comissão Temporária pela Mesa, para submeter à revisão do texto. Dessa forma, novas modificações que sejam incluídas no PL 6814/2017 não estão contempladas.
} 


\section{Abstract \\ Law No. 8.666/93 and PL No. 559/13: The main changes to the public manager}

The draft law - Bill No. 559/13, which aims to replace the current Public Procurement Law - Law 8.666 / 93, is pending in the Senate along with the Law of Trading - Law No. 10,520 / 02 and the Differentiated Regime of Public Procurement (DRC) - Law No. 12,462 / 11. It is vital for the public manager to know the rules and laws related to the bid, and Bill No. 559/13 in progress, to perform more efficiently, with greater speed and quality of their functions. This paper presents a summary of a research whose aim was to identify the main changes to the public manager with the change of Law No. 8,666 / 93 to Bill No. 559/13, analyzing the items and describing the major strengths and weaknesses, advantages and disadvantages of these changes. The study was based on theoretical references on the public manager and the importance of bidding, on public auctions, and on major advances in legislation. It also reviews the Law No. 8.666 / 93 and its modifications, the Bill No. 559/13, the Law No. 12,462 / 11 and, finally, the Law No. 10, 520/02. The survey compares the Law 8.666 / 93 to the Bill No. 559/13, identifying the main changes made, according to the authors researched. This paper focuses on the 4 items and 11 sub-items that propose changes, of which 4 were considered as beneficial changes and 11 as harmful to the public administrator and public administration. Most of the changes outlined represent drawbacks to public administration. This study stresses that the Procurement Law should only be changed after a thorough study and comparative evaluation of the minimum parameters to provide greater security to possible changes. The mere substitution of a standard for another or its repetition does not lead to long-awaited improvement of public procurement. A new law should lead to a permanent instrument.

Keywords: Procurement law. Law 12.462/11. Law 10.520/02.

\section{Introdução}

Após 22 anos da implementação da Lei de Licitações, considerada pioneira na época por regrar as contratações nas diferentes esferas públicas: União, Estado e Municípios, a Lei 꾸 8.666 (BRASIL, 1993) acabou por acumular muitas críticas no decorrer dos anos. As principais críticas a atribuem como burocrática e pouco eficiente diante do cenário atual e das inovações tecnológicas disponíveis, apesar de ter surgido como contraponto aos diversos escândalos de corrupção do governo Collor e com a expectativa de moralizar as aquisições e contratações públicas. 
No sentido de aperfeiçoar os recursos nas contratações e aquisições da Administração Pública, proporcionando eficiência e celeridade, está em tramitação a proposta do Projeto de Lei - PL no 559 (BRASIL, 2013), a qual visa substituir a atual Lei de Licitações - Lei no 8.666 (BRASIL, 1993), a Lei do Pregão - Lei № 10.520 e o Regime Diferenciado de Contratações Públicas - Lei № 12.462 . A nova proposta pretende tornar o processo licitatório menos burocrático e alinhado às novas tecnologias, tornando a Administração Pública mais célere e eficaz nas contratações como na iniciativa privada.

Neste contexto, cabe destacar a importância da licitação dentro da Administração Pública, e a atuação do gestor público como agente promovedor da eficiência e qualidade na provisão de bens e serviços. Uma maior eficiência nas licitações da Administração Pública é um dos maiores desafios da atualidade, significa que os recursos de impostos e contribuições arrecadados da sociedade serão revertidos para que ela cumpra seu principal objetivo, que é o de atender e prover bens e serviços públicos à população.

Dessa forma, é de fundamental importância ao gestor público conhecer as normas e Leis referentes à Licitação, e no caso desse projeto de Lei em tramitação, identificar as vantagens e desvantagens, pontos positivos e negativos que poderá ocorrer com essa nova proposta, podendo assim, conhecer e promover cada vez mais o papel que lhe cabe na esfera da Administração Pública, bem como desempenhar de forma mais eficiente, com maior agilidade e qualidade as suas funções.

Este artigo tem como objetivo maior verificar, analisar e apresentar as principais mudanças para o gestor público apresentadas no PL no 559 (BRASIL, 2013) em comparação com a lei vigente, Lei o 8666 (BRASIL, 1993). Propondo-se dentro deste objetivo conceituar os principais temas, licitação e gestor público, passando por um breve histórico e contextualização das principais leis referentes à licitação. Além de identificar e analisar as principais mudanças, citando e relacionando as principais vantagens e desvantagens das duas redações de acordo com diferentes autores e entidades representativas.

No atual cenário das contratações públicas e escândalos vinculados as mesmas, há a necessidade evidente de haver uma lei eficiente que possua mecanismos que impeçam as fraudes e que promovam a celeridade e qualidade nas licitações, bem como da Administração Pública e do gestor público em promover contratações e aquisições que atendam às necessidades latentes da sociedade e cumpram com sua função social, os quais são pontos de interesse que justificam a escolha pelo tema. Aliados a esses pontos, pode-se citar a experiência própria como gestora de contratos na esfera pública - empresa CEEE-D, e a necessidade de conhecer as regras e normas que norteiam o serviço desempenhado visando uma maior qualificação profissional.

De forma similar, pode-se destacar a grande repercussão em matérias e entre entidades representativas como Conselhos de classe da Arquitetura e Urbanismo, Tribunais de Contas e demais entidades, sobre a redação proposta no projeto de Lei - PL № 559 (BRASIL, 2013), os quais geraram diversas matérias, ofícios e manifestações técnicas em desaprovação. Tais repercussões demonstram além da importância, a relevância de se abordar e discutir o tema. 


\section{Materiais e Métodos}

A pesquisa relatada neste artigo foi de natureza bibliográfica constituída por levantamento de pesquisas publicadas, pertinentes ao tema, conceitos e formulações de autores com conhecimento renomado no assunto. Empregou-se também a pesquisa documental, utilizando-se documentos elaborados por entidades conceituadas, como Instituto de Pesquisa Econômica Aplicada (IPEA), Conselho de Associação Nacional dos Auditores de Controle Externo dos Tribunais de Contas do Brasil (ANTC), entre outros documentos pertinentes ao tema inclusive publicações online, além da utilização principalmente de normas e Leis relacionados à licitação

A partir dos dados levantados buscou-se conhecer as principais publicações e documentos na área de licitações, as quais serviram inclusive para justificar as contribuições e limites utilizados na pesquisa, propiciando também a coleta de informações, conhecimentos sobre a área de licitações e as mudanças propostas, as quais foram utilizadas para a elaboração da fundamentação teórica. Todas estas publicações foram lidas, resumidas, sintetizadas e seus principais conteúdos utilizados na análise deste trabalho.

No que se refere à tipologia e objetivos, a pesquisa empregou a pesquisa comparativa, através da qual se comparou a Lei de licitações no 8.666 (BRASIL, 1993) vigente com a proposta de alteração apresentada no Projeto de Lei PL 559 (BRASIL, 2013). Procurou-se correlacionar as duas, no intuito de verificar quais os principais pontos de mudança e suas características, para o gestor público. O trabalho utilizou também a pesquisa descritiva e exploratória, se propondo a analisar, correlacionar a lei atual (Lei no 8.666/93) com a proposta para substituição (PL № 559/13) e verificar quais as alterações mais importantes, que ocorrerão se aprovado o projeto de lei, para o gestor público.

A utilização dos critérios vantagens e pontos positivos, nessa pesquisa, levou em consideração o conjunto de alterações ou itens os quais propiciam ao gestor público benefícios e celeridade nos processos licitatórios, procedimentos menos burocráticos para tomada de decisões e execução de ações, os quais pressupõem um desempenho das atividades de forma mais eficiente e eficaz, com qualidade e alcance dos resultados esperados sem representar perda ao erário público, atrasos ou qualidade inferior de serviços, bens ou obras.

De forma análoga, os aspectos negativos ou os que representam desvantagens foram considerados o conjunto de alterações ou itens que favoreçam as fraudes, conluios entre empresas, danos ao erário público, superfaturamentos com a consequente baixa na qualidade de obras, serviços e projetos, definições vagas e pouco objetivas do objeto a ser licitado, além de outros similares que são danosos aos interesses públicos e a atuação do gestor público.

\section{Lei n. 8.666/93 - Lei Geral de Licitações}

A Lei o 8.666 (BRASIL, 1993) é a lei que regulamenta o art. 37 incisos XXI da Constituição Federal (BRASIL, 1988), tratando especificamente das licitações e contratos da Administração Pú- 
blica, instituindo normas para licitação e contratos. A Lei no 8.666 (BRASIL, 1993), conhecida como Lei de Licitações, com a relatoria do então Deputado Luiz Roberto Ponte, trouxe ao país grandes avanços em direção à moralização dos processos de aquisição de bens e serviços por parte do Governo. Elaborada e promulgada ainda sob os ânimos da C.F. (BRASIL, 1988), a lei consagrou o menor preço como o princípio basilar das compras governamentais. Fiuzza e Medeiros (2014, p.1) descrevem o cenário político que culminou na elaboração e instauração da Lei de Licitações.

A Lei ํo 8.666/1993, que rege as compras públicas, estabelecendo princípios gerais e definições, veio como uma resposta aos sucessivos escândalos do governo Collor e dos Anões do Orçamento, e instituiu controles mais rígidos sobre as licitações.

Nesse cenário, a Lei o 8.666 (BRASIL, 1993) teve como um dos seus propósitos formalizar os procedimentos para compras e contratações, de modo a convergir com o viés mais "democrático" incorporado à C.F. (BRASIL, 1988).

Este documento, influenciado pela C.F. (BRASIL, 1988) e o cenário político da época, passou a ser a principal referência para as operações legais licitatórias. Trouxe na sua formulação, várias colocações já existentes em leis anteriores, porém com novas observações, Bicalho (2014, p. 11) comenta a respeito:

É imperioso reconhecer que um dos maiores méritos da Lei no 8.666/93 foi ter se constituído como a base de construção da farta e rica jurisprudência hoje existente em tema de licitações, em especial no âmbito do Tribunal de Contas da União.

Ao encontro do citado por Bicalho (2014), mas ampliando e apontando de forma crítica, Spricigo e Fonseca (2008) ressaltam que apesar do seu caráter modernizador, a Lei ํㅡ 8.666/93 apresenta diversos problemas de ordem prática em razão de sua estrutura altamente burocrática. No entanto, é importante observar que, no contexto histórico, ela teve uma importância fundamental, mas para o novo contexto mundial, na era da globalização, a Lei no 8.666/93 mostra sinais de defasagem segundo os autores.

\section{Modificações da Lei n. 8.666/93}

Ao longo de vinte e dois anos de existência a Lei de Licitações, Lei № 8.666 (BRASIL, 1993), foi alterada por 61 medidas provisórias (MPs) e dezenove leis, um total de oitenta normas, ou quatro normas por ano. Além das modificações implementadas outras tantas iniciativas tramitaram no Congresso, mas a tentativa que mais progrediu foi o Projeto de Lei do Executivo (PL) no 7.709 (BRASIL, 2007), que tramitou com bastante rapidez na Câmara dos Deputados e logo foi remetido ao Senado.

O substitutivo recém-aprovado ao Projeto de Lei (PL) no 7.709 (BRASIL, 2007), o qual no Senado foi renomeado e renumerado como Projeto de Lei da Câmara (PLC) № 32 (BRASIL, 2007), esteve em regime de urgência até final de junho de 2007 quando o Executivo solicitou a extinção da 
urgência. Em abril de 2009, porém, ele foi engavetado na Secretaria de Coordenação Legislativa do Senado aguardando a inclusão do Dia.

Neste interim, o Poder Executivo interveio na legislação com uma ação paralela, motivado por uma avaliação unânime de que a Lei de Licitações vigente propiciava o atraso e a paralisia de obras. Diante da necessidade de acelerar obras com vistas à preparação da infraestrutura brasileira para os grandes eventos esportivos, e diante do prazo indefinido de tramitação da reforma, o Executivo optou por uma minirreforma temporária e localizada. Foi criado o Regime Diferenciado de Contratações Públicas - RDC (BRASIL, 2011), posteriormente estendido a obras e serviços de engenharia no âmbito do Sistema Único de Saúde (SUS), e que paulatinamente vai sendo proposto para novas aplicações por meio de PL's e medidas provisórias (MPs). Toda essa evolução seguiu uma tendência de aprimoramento do sistema, numa vertente mais voltada para a busca da eficiência e agilidade nas relações de contrato entre público e privado, além da perspectiva de inclusão das novas tecnologias para amparar os processos licitatórios.

Nesses quase 23 anos de vigência da Lei no 8.666 (BRASIL, 1993), as tentativas de sua alteração e modernização foram frustradas, seja pelos interesses econômicos ou políticos envolvidos. O PL № 32 (BRASIL, 2007) foi o projeto mais próximo de promover essa alteração, contudo não vingou, e seu sucessor PL no 559 (BRASIL, 2013) é a mais recente tentativa de alteração da Lei de Licitação vigente.

\section{PL no 559/13- Projeto de reforma da Lei de Licitações}

Em 3 de junho de 2013, pelo Ato do Presidente do Senado Federal no 19/2013, foi criada uma Comissão Especial Temporária de modernização da Lei de Licitações e Contratos (CTLICON). Ela foi instalada em 13 de junho de 2013, funcionando sob a presidência do senador Vital do Rêgo e relatoria da senadora Kátia Abreu, na mesma data foi aprovado o plano de trabalho e em 26 de junho de 2013 foi realizada a primeira audiência pública da comissão, na qual foram feitas exposições orais e submissões por escrito por representantes da iniciativa privada.

O texto elaborado conta com 175 artigos e tramita no Senado como Projeto de Lei - PL sob o número 559 (BRASIL, 2013), atualmente sob a responsabilidade da Comissão de Assuntos Econômicos e com a apresentação de 64 emendas ao projeto elaborado. Bicalho (2014), comenta que a referida comissão tem por finalidade atualizar e modernizar a Lei ํㅜ 8.666/93. Dessa forma, a proposta, disponível no sítio do Senado Federal, prevê com a instituição da nova legislação sobre licitações e contratos administrativos a revogação das Leis № 8.666 (BRASIL, 1993), principal norma aplicável às licitações hoje, Lei no 10.520 - pregão (BRASIL, 2002), além dos art. 1 a 47 da Lei no 12.462 - Regime Diferenciado de Contratações Públicas (RDC) (BRASIL, 2011).

O texto apresentado do PL no 559 (BRASIL, 2013), incorpora diversas nuances da sistemática do RDC (BRASIL, 2011), bem como dos demais diplomas que revoga, modernizando, segundo os responsáveis pela elaboração, o sistema legal das contratações públicas em seu conjunto. Essa proposta consta na exposição de motivos, presente no relatório final da CTLICON, sendo citada por Bicalho (2014, p.12). 
Reconhecidos os êxitos da legislação vigente, não faria sentido a simples substituição de suas cláusulas por regramento inteiramente novo. Por isso, em grande medida, o projeto pode ser entendido como uma proposta de compilação dos diplomas legais citados, acrescida de inovações.

\section{Lei no 12.462/11 - Regime Diferenciado de Contratações Públicas - RDC}

A Lei no 12.462 - Regime Diferenciado de Contratações Públicas (RDC) (BRASIL, 2011) foi implementado para ser aplicável exclusivamente às licitações e contratos necessários à realização da Copa das Confederações (FIFA) em 2013, Copa do Mundo em 2014, Jogos Olímpicos e Paraolímpicos de 2016, de obras de infraestrutura e contratação de serviços para os aeroportos das capitais dos Estados, distantes até $350 \mathrm{~km}$ (trezentos e cinquenta quilômetros) das cidades sedes dos mundiais. Posteriormente, em 2012, foi ampliada a atuação do RDC (BRASIL, 2011) para as ações integrantes do Programa de Aceleração do Crescimento (PAC) e obras e serviços de engenharia no âmbito do Sistema Único de Saúde (SUS).

O RDC (BRASIL, 2011) não segue os procedimentos e diretrizes previstos na Lei de Licitações, exceto alguns artigos da Lei no 8.666 (BRASIL, 1993) que são previstos em poucas subseções do RDC (BRASIL, 2011), sendo implementado inicialmente sob o argumento de agilizar as obras para os eventos esportivos previstos para acontecerem no Brasil. Nesse regime de contratação o grande diferencial é a possibilidade de contratação por empreitada integral, na qual se contrata um empreendimento em sua integralidade sob inteira responsabilidade da contratada até a sua entrega.

Além disso, prevê a possibilidade de o orçamento estimado da licitação ser divulgado apenas após o término da licitação e ter-se um vencedor, ou não ser divulgado. Inclui também a possibilidade de contratação de serviços e obras, inclusive as de engenharia civil, somente com um préprojeto quando for utilizado o regime de contratação integrada. Outro dispositivo utilizado no RDC (BRASIL, 2011) é a inversão de fases, na qual a habilitação ocorre após o julgamento das propostas da licitação, sendo somente realizado para o vencedor do certame.

\section{Lei no 10.520/02 - Modalidade de licitação pregão}

A Lei № 10.520 (BRASIL, 2002) instituiu para aquisição de bens e serviços comuns a modalidade pregão. Nesta lei foi incluída a possibilidade de realização do pregão de forma presencial ou por meio da utilização de recursos de tecnologia da informação, conhecido como pregão eletrônico. Pela referida lei, consideram-se bens e serviços comuns aqueles cujos padrões de desempenho e qualidade possam ser objetivamente definidos pelo edital, por meio de especificações usuais no mercado. Essa modalidade baseia-se na utilização do critério menor preço para o julgamento e classificação das propostas, utilizando a inversão de fases, de forma semelhante ao RDC (BRASIL, 2011), sendo a fase de habilitação posterior a de julgamento. 
Com a implantação do sistema de aquisição eletrônico Comprasnet, portal de compras do governo federal na Internet, houve a regulamentação do pregão eletrônico através da promulgação

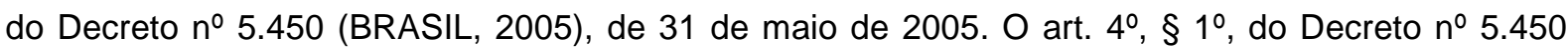
(BRASIL, 2005), regulamenta e torna obrigatória a utilização do pregão na forma eletrônica, para aquisição de bens e serviços comuns, salvo nos casos de comprovada inviabilidade, a ser justificada pela autoridade competente. Esta modalidade de licitação possui como importante característica a celeridade nos processos licitatórios, minimizando custos para a Administração Pública e vem se consolidando como a principal forma de contratação do Governo Federal.

\section{Alteração da Lei de Licitações - Da Lei no 8.666/93 ao PL no 559/13}

Foram selecionados para a pesquisa deste artigo 4 (quatro) itens e 11 (onze) subitens considerados relevantes, tanto por terem sido mais comentados e analisados nas manifestações de entidades representativas e matérias vinculadas sobre a proposta de alteração, como pela própria experiência como gestora de contratos na Administração Pública, fator que também contribuiu para a seleção dos principais itens. Outro fator determinante dessa delimitação dos itens analisados foi o fator tempo, adequado ao prazo proposto para um curso de especialização, mas que impõe como limitante a realização de uma seleção dos itens e não uma abordagem completa de todos os itens alterados.

O resultado da comparação e das análises realizadas demonstrou que algumas alterações propostas advêm de procedimentos já utilizados em outras leis, como a inversão de fases, já é utilizada nas Leis do RDC (BRASIL, 2011) e do Pregão (BRASIL, 2002), bem como a utilização preferencial da forma eletrônica, ainda que limitada a bens e serviços comuns pelo pregão eletrônico. Dessa forma, percebeu-se tanto pelo estudo comparativo como pelos autores e entidades pesquisados que a redação do projeto de lei agrupa em sua redação muitos dos mecanismos e procedimentos já adotados em outras leis. Somado a inclusão de mecanismos que permitem fraudes, superfaturamento de obras e danos ao erário público, além de impactos negativos diretos na atuação dos órgãos de controle e fiscalização.

Algumas das mudanças apresentadas trazem benefícios aos gestores, à Administração Pública e à sociedade. São elas:

a) Extinção das modalidades Tomada de Preços e Carta-Convite, principalmente por permitirem fraudes e conluios entre empresas;

b) Utilização preferencial da forma eletrônica nas licitações, quando usada somente para a aquisição de bens e serviços comuns;

c) Previsão de publicação dos procedimentos licitatórios em sítios eletrônicos oficiais e a não alteração dos prazos iniciais, os quais agilizam as formalidades e reduzem custos de publicação em Diários Oficiais e jornais;

d) Inversão de fases, prevendo que a fase de habilitação da empresa seja após os lances e propostas ou o julgamento, agilizando o processo uma vez que só serão analisadas as documentações referentes à empresa vencedora. 
Contudo, a grande maioria das alterações levantadas foi considerada negativa, causando desvantagens principalmente aos interesses e erário públicos, e ao controle e fiscalização dos atos administrativos praticados. As mudanças apresentadas que trazem desvantagens aos gestores, à Administração Pública e à sociedade em geral, são:

a) Tamanho do projeto de lei, no qual se buscava uma redação menos burocrática e sem itens desnecessários, mas que possui na redação 50 artigos a mais que a lei atual, além de possuir redação confusa, burocrática e sem uma boa técnica legislativa, tentando reunir muitos interesses diversos e fazer um apanhado das diferentes leis que tratam do tema criando um apanhado de normas não harmônicas entre si.

b) Alteração do termo "projeto básico" para "projeto completo", retirando com a nova redação os elementos que vinham elencados na lei vigente e que definiam os itens necessários e suficientes que deviam estar presentes no projeto básico. Deixando um conceito vago e sem delimitação objetiva para o gestor público;

c) Utilização da contratação integrada, extensível para qualquer obra e serviço de engenharia, considerada um dos maiores malefícios da nova redação, pois permite a contratação integral de uma obra a partir apenas de um simples anteprojeto, tendo como consequência obras de qualidade inferior, superfaturamento e vários aditivos. Além disso, abre precedentes para as empresas vencedoras não seguirem os parâmetros de composição de preços baseados nos do SICRO e SINAPI, como as demais empresas em outros modelos de contratações;

d) Previsão de orçamento sigiloso é outro item advindo do RDC (BRASIL, 2011), o qual deixa a critério discricionário do gestor público a decisão de tornar ou não público o orçamento. Impedindo no caso do sigilo o conhecimento e a publicidade desses valores gastos a qualquer cidadão, o que afronta a própria C.F (BRASIL, 1988), além de frustrar qualquer possibilidade de futura denúncia de irregularidades ou valores abusivos;

e) Previsão de utilização da forma eletrônica para a contratação de obras e serviços de engenharia pelo critério de julgamento menor preço, abrindo novamente precedente para a contratação de obras de qualidade inferior, pois somente o critério preço é levado em consideração. Ainda neste quesito a nova redação admite a licitação presencial, a qual possibilita fraudes e conluio, inclusive a diminuição da competitividade;

f) Utilização de pregão e ata de registro de preço para contratação de projetos e obras de engenharia, a qual da mesma forma que o item "d" seria utilizado apenas o critério menor preço, causando os mesmos danos que os citados naquele item;

g) Possibilidade de participação na execução da obra do autor do projeto, inclusive o seu ressarcimento caso não vença a licitação para a execução, sem nenhum critério de valores, aceitação ou regras para pagamento;

h) Análise prévia e aprovação para qualquer contratação direta a ser realizada é outro item dos mais criticados por causar impacto no controle e atuação dos órgãos de fiscalização, como Tribunais de Contas, inviabilizando a sua atuação, pois ou fariam uma análise superficial ou demorariam em demasia causando nas duas hipóteses perdas e consequências danosas; 
i) Limitação do poder cautelar e controle prévio de editais e contratos, os quais preveem que a suspensão cautelar é privativa da Administração, Tribunais de Contas e Poder Judiciário. Os editais devem ser analisados em 90 dias sob pena de não poderem mais ser suspensos por inconformidades. Tais regras criam embaraços diversos para impedir a atuação dos órgãos, atribuindo regras danosas e fora das competências a eles atribuídas;

j) Possibilidade de criminalizar a suspensão de contrato, incluindo na atual redação do projeto de Lei, mecanismos de infração penal com caráter criminalizador. Este dispositivo enseja que os julgadores dos Tribunais possam ser considerados sujeitos ativos do crime;

k) Possibilidade de responsabilizar o denunciante de irregularidade é outro item criticado, pois afetam a fiscalização e desestimulam a participação da sociedade ao prever penalidades de detenção e multa, caso a irregularidade não se confirme. Esse dispositivo de penalização é uma afronta a C.F (BRASIL, 1988), a qual estabelece que qualquer cidadão pode denunciar irregularidades ou ilegalidades.

Portanto, das mudanças pesquisadas com a alteração para o PL n 559 (BRASIL, 2013), as que trariam pontos positivos e benéficas ao gestor público, foram identificadas em apenas 4 (quatro) itens. A grande maioria, 11 (onze) itens que foram levantados, podem ser considerados como danosos para os interesses públicos e com diversos pontos negativos ao gestor público.

O Quadro 1 correlaciona as principais mudanças para o gestor público, da Lei № 8.666/93 (BRASIL, 1993) para o PL no 559/13 (BRASIL, 2013), incluindo os aspectos positivos ou negativos levantados em cada uma destas alterações de acordo com os diferentes autores pesquisados e manifestações das diversas entidades representativas.

Quadro 1 - Principais mudanças, da Lei nำ 8.666/93 para o PL ํㅜ 559/13, incluindo os aspectos positivos ou negativos levantados.

\begin{tabular}{|c|c|c|c|c|}
\hline Item/ Sub item & Lei no 8.666/93 & PL no 559/13 & Aspectos Positivos & Aspectos Negativos \\
\hline $\begin{array}{l}4.1 \text { Estrutura da } \\
\text { Lei- Quantidade } \\
\text { de artigos e ca- } \\
\text { pítulos }\end{array}$ & $\begin{array}{l}126 \text { artigos } \\
6 \text { capítulos }\end{array}$ & $\begin{array}{l}176 \text { Artigos } \\
14 \text { capítulos }\end{array}$ & & $\begin{array}{l}\text { A redação do projeto está } \\
\text { mais extensa do que a } \\
\text { atual Lei de Licitações, } \\
\text { podendo burocratizar ain- } \\
\text { da mais as licitações e } \\
\text { tornar menos céleres as } \\
\text { contratações; } \\
\text { Possui texto confuso e } \\
\text { burocrático, sem boa téc- } \\
\text { nica legislativa, de difícil } \\
\text { interpretação com concei- } \\
\text { tos abrangentes e pouco } \\
\text { objetivos ao gestor públi- } \\
\text { co; } \\
\text { Tenta reunir muitos inte- } \\
\text { resses e leis, criando um } \\
\text { apanhado de normas não }\end{array}$ \\
\hline
\end{tabular}




\begin{tabular}{|c|c|c|c|c|}
\hline Item/ Sub item & Lei $n \div 8.666 / 93$ & PL no 559/13 & Aspectos Positivos & Aspectos Negativos \\
\hline & & & & harmônicas entre si. \\
\hline $\begin{array}{l}4.2 \text { Alteração do } \\
\text { termo "projeto } \\
\text { básico" para } \\
\text { "projeto comple- } \\
\text { to" }\end{array}$ & $\begin{array}{l}\text { Cap. I, seção II, } \\
\text { art. } 6 \text {, inciso IX }\end{array}$ & $\begin{array}{l}\text { Cap. I, se- } \\
\text { ção III, inciso } \\
\text { XXXIV }\end{array}$ & & $\begin{array}{l}\text { A redação do projeto ex- } \\
\text { clui os elementos elenca- } \\
\text { dos na Lei no } 8.666 / 93 \text {, os } \\
\text { quais são considerados } \\
\text { fundamentais para a ca- } \\
\text { racterização do projeto } \\
\text { básico; } \\
\text { Com a exclusão dos ele- } \\
\text { mentos o conceito de pro- } \\
\text { jeto completo fica abran- } \\
\text { gente e sem delimitação } \\
\text { objetiva, utilizando termos } \\
\text { vagos como "elementos } \\
\text { necessários e suficientes"; } \\
\text { Deixa a critério do gestor, } \\
\text { poder discricionário, para } \\
\text { a escolha dos elementos e } \\
\text { critérios a serem adota- } \\
\text { dos. }\end{array}$ \\
\hline $\begin{array}{l}\text { 4.3.1 Extinção } \\
\text { de modalidades } \\
\text { licitatórias- To- } \\
\text { mada de Preços } \\
\text { e Carta-convite }\end{array}$ & $\begin{array}{l}\text { Cap. II, seção I, } \\
\text { art. 22, inciso II e } \\
\text { III, parágrafo §º } \\
\text { e §3o } \\
\text { Cap. II, seção I, } \\
\text { art. } 23\end{array}$ & $\begin{array}{l}\text { Cap. II, se- } \\
\text { ção II, art. } 36\end{array}$ & $\begin{array}{l}\text { Reduz-se a possibilidade } \\
\text { de fraudes e burlas; } \\
\text { Existem outras modalida- } \\
\text { des disponíveis ao gestor; } \\
\text { Existe a alternativa da } \\
\text { realização de pregões } \\
\text { eletrônicos em substitui- } \\
\text { ção as duas modalidades, } \\
\text { agilizando e reduzindo os } \\
\text { prazos de execução da } \\
\text { licitação. }\end{array}$ & \\
\hline $\begin{array}{l}\text { 4.3.2.1 Contra- } \\
\text { tação integrada }\end{array}$ & $\begin{array}{l}\text { Não há previsão } \\
\text { deste tipo de con- } \\
\text { tratação }\end{array}$ & $\begin{array}{l}\text { Cap. I, seção } \\
\text { III, art. 5, } \\
\text { inciso XVI } \\
\text { (definição) } \\
\text { Cap. V, se- } \\
\text { ção II, art. } \\
75 \text {, inciso V }\end{array}$ & & $\begin{array}{l}\text { Amplia o seu uso para } \\
\text { todas as obras e serviços } \\
\text { de engenharia em todas } \\
\text { as esferas administrativas } \\
\text { Utilização apenas de an- } \\
\text { teprojeto, causando inú- } \\
\text { meras consequências } \\
\text { como aditamentos, super- } \\
\text { faturamento de obras, uso } \\
\text { de materiais de baixa qua- } \\
\text { lidade, atrasos entre ou- } \\
\text { tros; }\end{array}$ \\
\hline
\end{tabular}




\begin{tabular}{|c|c|c|c|c|}
\hline Item/Sub item & Lei no 8.666/93 & PL no 559/13 & Aspectos Positivos & Aspectos Negativos \\
\hline & & & & $\begin{array}{l}\text { Empresa elabora o projeto } \\
\text { completo e executivo, } \\
\text { executa/constrói a obra e } \\
\text { opera; não há dissociação } \\
\text { e independência entre as } \\
\text { fases; } \\
\text { Possibilidade de utilização } \\
\text { de valores acima dos indi- } \\
\text { cados pelo SINAPI e SI- } \\
\text { CRO, parâmetros para a } \\
\text { composição de custos- } \\
\text { orçamento, e de serem } \\
\text { dispensados de entregar } \\
\text { ao contratante o detalha- } \\
\text { mento dos quantitativos, } \\
\text { custos unitários, BDI e ES; } \\
\text { Não contempla o risco } \\
\text { contratual, o qual acaba } \\
\text { mantendo a atribuição do } \\
\text { risco à Administração, } \\
\text { nem prevê a inclusão de } \\
\text { matriz de risco nos ante- } \\
\text { projetos; } \\
\text { Dificuldade de fiscalização } \\
\text { pelos órgãos competen- } \\
\text { tes; } \\
\text { Permite "acertos" com o } \\
\text { vencedor, pois não há } \\
\text { parâmetros para compa- } \\
\text { ser executado. }\end{array}$ \\
\hline $\begin{array}{l}\text { 4.3.2.2 Orça- } \\
\text { mento Sigiloso }\end{array}$ & $\begin{array}{l}\text { Não há previsão } \\
\text { de orçamento } \\
\text { sigiloso }\end{array}$ & $\begin{array}{l}\text { Cap. II, se- } \\
\text { ção I, art. } 23\end{array}$ & $\begin{array}{l}\text { Defensores do RDC, ar- } \\
\text { gumentam que sem co- } \\
\text { nhecer o valor de referên- } \\
\text { cia- orçamento, os concor- } \\
\text { rentes apresentariam pro- } \\
\text { postas iniciais inferiores e } \\
\text { inibiria a formação de } \\
\text { acertos prévios de valores } \\
\text { entre eles. }\end{array}$ & $\begin{array}{l}\text { Deixa a opção do orça- } \\
\text { mento sigiloso ao gestor } \\
\text { público; } \\
\text { Danosa aos interesses } \\
\text { públicos, não ocorrendo à } \\
\text { publicidade dos valores } \\
\text { praticados à sociedade. } \\
\text { Frustra a possibilidade de } \\
\text { denúncias ou investiga- } \\
\text { ções que partam do indi- } \\
\text { víduo ou sociedade que } \\
\text { considere os valores abu- }\end{array}$ \\
\hline
\end{tabular}




\begin{tabular}{|c|c|c|c|c|}
\hline Item/Sub item & Lei no 8.666/93 & PL no 559/13 & Aspectos Positivos & Aspectos Negativos \\
\hline & & & & $\begin{array}{l}\text { sivos ou com irregularida- } \\
\text { des; } \\
\text { Dificulta e/ou impede a } \\
\text { fiscalização, pois prevê a } \\
\text { utilização de preços fixa- } \\
\text { dos entre as partes, con- } \\
\text { tratante e contratado, sem } \\
\text { a utilização de valores de } \\
\text { referência do SINAPI e } \\
\text { SICRO; } \\
\text { Não propiciou, nos contra- } \\
\text { tos realizados com esta } \\
\text { opção, a redução espera- } \\
\text { da nas propostas iniciais. }\end{array}$ \\
\hline $\begin{array}{l}\text { 4.3.3 Utilização } \\
\text { preferencial da } \\
\text { forma eletrônica } \\
\text { nas licitações }\end{array}$ & $\begin{array}{l}\text { Não há previsão, } \\
\text { não se dispunha } \\
\text { desta ferramenta } \\
\text { nos anos da for- } \\
\text { mulação e im- } \\
\text { plementação da } \\
\text { lei. }\end{array}$ & $\begin{array}{l}\text { Cap. II, se- } \\
\text { ção I, art. 19, } \\
\text { parágrafo §2 }\end{array}$ & $\begin{array}{l}\text { Benéfico ao gestor público } \\
\text { quando aplicado nas } \\
\text { mesmas condições da } \\
\text { atual Lei no } 10.520 \text { - pre- } \\
\text { gão e Decreto no } 5.450 \text { - } \\
\text { pregão eletrônico, somen- } \\
\text { te para contratação de } \\
\text { bens e serviços comuns. } \\
\text { Tornam mais célere as } \\
\text { contratações, mais eco- } \\
\text { nômico o processo e com } \\
\text { mais competitividade a } \\
\text { licitação. }\end{array}$ & $\begin{array}{l}\text { Abre precedentes para a } \\
\text { contratação de projetos, } \\
\text { obras e serviços de enge- } \\
\text { nharia pelo critério menor } \\
\text { preço; } \\
\text { Possibilita a contratação } \\
\text { de obras e serviço com } \\
\text { qualidade inferior, pois o } \\
\text { único critério é o menor } \\
\text { preço para determinar o } \\
\text { vencedor do certame; } \\
\text { Admite a realização na } \\
\text { forma presencial, o que } \\
\text { diminui a competitividade, } \\
\text { restringindo o certame, } \\
\text { possibilitando o conluio e } \\
\text { o direcionamento da licita- } \\
\text { ção, abrindo a porta para } \\
\text { a perda de eficiência e de } \\
\text { economicidade. }\end{array}$ \\
\hline $\begin{array}{l}\text { 4.3.4 Utilização } \\
\text { de pregão e ata } \\
\text { de registro para } \\
\text { contratação de } \\
\text { projetos e obras } \\
\text { de engenharia }\end{array}$ & Não há previsão & $\begin{array}{l}\text { Cap. I, seção } \\
\text { III, incisos VI, } \\
\text { XXXI, XXVII } \\
\text { e XXVIII }\end{array}$ & & $\begin{array}{l}\text { Abre precedentes para a } \\
\text { contratação de projetos, } \\
\text { obras e serviços de enge- } \\
\text { nharia pelo critério menor } \\
\text { preço; } \\
\text { Possibilita a contratação } \\
\text { de obras e serviço com } \\
\text { qualidade inferior, pois o } \\
\text { único critério é o menor }\end{array}$ \\
\hline
\end{tabular}




\begin{tabular}{|c|c|c|c|c|}
\hline Item/Sub item & Lei no 8.666/93 & PL no 559/13 & Aspectos Positivos & Aspectos Negativos \\
\hline & & & & $\begin{array}{l}\text { preço para determinar o } \\
\text { vencedor do certame. }\end{array}$ \\
\hline $\begin{array}{l}\text { 4.3.5 Publicação } \\
\text { dos procedimen- } \\
\text { tos licitatórios e } \\
\text { prazos dos atos }\end{array}$ & $\begin{array}{l}\text { Cap. II, seção I } \\
\text { art. 21, inciso I a } \\
\text { III } \\
\text { Cap. II, seção I, } \\
\text { art. 21, parágrafo } \\
\text { §4ํㅗ }\end{array}$ & 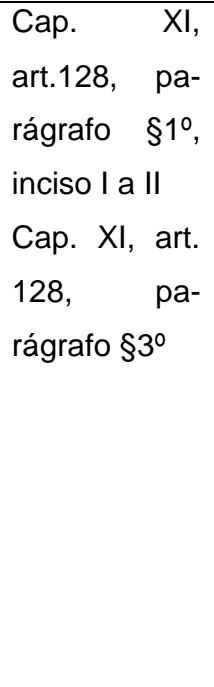 & $\begin{array}{l}\text { Reduz custos com a pos- } \\
\text { sibilidade de fazer a divul- } \\
\text { gação/publicidade dos } \\
\text { procedimentos licitatórios } \\
\text { em site eletrônico; } \\
\text { Reduz prazos, ao não } \\
\text { permitir que a cada modifi- } \\
\text { cação no instrumento con- } \\
\text { vocatório reabra o prazo } \\
\text { inicialmente estabelecido. } \\
\text { O que poderia aumentar } \\
\text { em muito os prazos para o } \\
\text { início da licitação. }\end{array}$ & \\
\hline $\begin{array}{l}\text { 4.3.6 Inversão } \\
\text { de fases }\end{array}$ & $\begin{array}{l}\text { Não há previsão } \\
\text { Cap. II, seção IV, } \\
\text { art. } 43\end{array}$ & $\begin{array}{l}\text { Cap. II, se- } \\
\text { ção I, art. } 19\end{array}$ & $\begin{array}{l}\text { Promove a agilidade para } \\
\text { a licitação, reduzindo o } \\
\text { tempo da fase de habilita- } \\
\text { ção, uma vez que somente } \\
\text { a empresa vencedora terá } \\
\text { sua documentação anali- } \\
\text { sada e não mais todas as } \\
\text { empresas antes do julga- } \\
\text { mento. }\end{array}$ & \\
\hline $\begin{array}{l}\text { 4.3.7 Possibili- } \\
\text { dade de partici- } \\
\text { pação na exe- } \\
\text { cução do autor } \\
\text { do projeto }\end{array}$ & $\begin{array}{l}\text { Cap. I, seção III, } \\
\text { art. } 9 \\
\text { Cap. I, seção III, } \\
\text { art. 9, parágrafo } \\
\S 1^{\circ}\end{array}$ & $\begin{array}{l}\text { Cap. I, seção } \\
\text { V, art. 14, } \\
\text { inciso I } \\
\text { Cap. I, seção } \\
\text { V, art. 14, } \\
\text { parágrafo §º } \\
\text { Cap. II, se- } \\
\text { ção I, art. 30, } \\
\text { parágrafo } \\
\text { único }\end{array}$ & & $\begin{array}{l}\text { Redação divergente, em } \\
\text { um artigo veda a partici- } \\
\text { pação e em outro abre } \\
\text { precedente; } \\
\text { Abre precedente, sem } \\
\text { regulamentação prévia e } \\
\text { definida, para pagamento } \\
\text { de projetos elaborados por } \\
\text { privados sem nenhum } \\
\text { critério, de aceitação ou } \\
\text { valores, ou qualquer parti- } \\
\text { cipação em concorrência } \\
\text { deste mesmo projeto; } \\
\text { Dificulta ou impede os } \\
\text { órgãos de controle ou de } \\
\text { fiscalização de atuarem, } \\
\text { pois não há estimativa de } \\
\text { custos a serem pagos } \\
\text { através de orçamento, não }\end{array}$ \\
\hline
\end{tabular}




\begin{tabular}{|c|c|c|c|c|}
\hline Item/Sub item & Lei no 8.666/93 & PL no 559/13 & Aspectos Positivos & Aspectos Negativos \\
\hline & & & & $\begin{array}{l}\text { há regulação para este } \\
\text { mecanismo. }\end{array}$ \\
\hline $\begin{array}{l}\text { 4.4.1 Consulta } \\
\text { prévia ao Tribu- } \\
\text { nal de Contas }\end{array}$ & Não há previsão & $\begin{array}{l}\text { Cap. III, se- } \\
\text { ção I, art. 56, } \\
\text { §5으 }\end{array}$ & & $\begin{array}{l}\text { A consulta prévia não faz } \\
\text { parte das funções consti- } \\
\text { tucionalmente atribuídas } \\
\text { aos Tribunais de Contas; } \\
\text { A redação atribui aos ór- } \\
\text { gãos de controle externo } \\
\text { atividade consultiva, típica } \\
\text { a iniciativa privada; } \\
\text { Pela redação os órgãos } \\
\text { irão tornar-se prévios ava- } \\
\text { lizadores de atos adminis- } \\
\text { trativos, substituindo a } \\
\text { atividade técnica e dos } \\
\text { gestores; } \\
\text { Inviabilizaria a atuação } \\
\text { dos tribunais, que diante } \\
\text { da incapacidade prática de } \\
\text { realizar o exame prévio de } \\
\text { todos os atos administrati- } \\
\text { vos pode produzir uma } \\
\text { análise superficial, ou num } \\
\text { exame mais detido de } \\
\text { cada ato tem-se o risco de } \\
\text { atrasar em demasia os } \\
\text { processos. }\end{array}$ \\
\hline $\begin{array}{l}\text { 4.4.2 Limitação } \\
\text { do poder caute- } \\
\text { lar e controle } \\
\text { prévio de editais } \\
\text { e contratos }\end{array}$ & $\begin{array}{l}\text { Não há previsão } \\
\text { similar ao dispos- } \\
\text { to no Cap. VIII, } \\
\text { art. } 93 \text { do projeto } \\
\text { de lei; } \\
\text { Cap. II, seção IV, } \\
\text { art.41, § 1ํ } \\
\text { Cap. VI, art. } 113\end{array}$ & $\begin{array}{l}\text { Cap. VIII, art. } \\
93 \text { e } \S 1^{\circ} \text { a } \S \\
4^{\circ} \\
\text { Cap. XIV, } \\
\text { art.150 e } \S 2^{\circ}\end{array}$ & & $\begin{array}{l}\text { Limita o poder dos Tribu- } \\
\text { nais de Contas e Poder } \\
\text { Judiciário, causa impacto } \\
\text { e delimita obrigações não } \\
\text { condizentes com suas } \\
\text { funções; } \\
\text { Não prevê a possibilidade } \\
\text { de qualquer cidadão ques- } \\
\text { tionar ou solicitar a impug- } \\
\text { nação, como na atual Lei } \\
\text { de Licitações; } \\
\text { A nova redação traz ina- } \\
\text { dequada abordagem ao } \\
\text { tratar conjuntamente e } \\
\text { indistintamente do exame } \\
\text { prévio de edital, da sus- }\end{array}$ \\
\hline
\end{tabular}




\begin{tabular}{|c|c|c|c|c|}
\hline Item/ Sub item & Lei $n=8.666 / 93$ & PL no 559/13 & Aspectos Positivos & Aspectos Negativos \\
\hline & & & & $\begin{array}{l}\text { pensão de licitações e } \\
\text { execução e contratos. A } \\
\text { competência dos Tribunais } \\
\text { de Contas limita-se a sus- } \\
\text { pensão da licitação, já a } \\
\text { suspensão da execução } \\
\text { do contrato é de compe- } \\
\text { tência privativa do Poder } \\
\text { Legislativo; } \\
\text { As condições estabeleci- } \\
\text { das na nova redação, } \\
\text { apresentam-se como po- } \\
\text { tencial impeditivo ou ao } \\
\text { menos inibidor da defesa } \\
\text { do erário e dos interesses } \\
\text { públicos; } \\
\text { As análises de cus- } \\
\text { to/benefício de cada alter- } \\
\text { nativa viável da situação, } \\
\text { inviabilizariam a eficácia e } \\
\text { atuação, além de possuir } \\
\text { inúmeras variáveis que } \\
\text { incidem na avaliação. }\end{array}$ \\
\hline $\begin{array}{l}\text { 4.4.3 Possibili- } \\
\text { dade de crimina- } \\
\text { lizar a suspen- } \\
\text { são do contrato }\end{array}$ & $\begin{array}{l}\text { Cap. IV, seção } \\
\text { IV, art. } 108\end{array}$ & $\begin{array}{l}\text { Cap. XIII, } \\
\text { seção IV, art. } \\
\text { 143, inciso XI }\end{array}$ & & $\begin{array}{l}\text { Acrescenta na própria } \\
\text { reação às penalizações a } \\
\text { serem aplicadas, crimina- } \\
\text { liza a suspensão de con- } \\
\text { trato, tornando os agentes } \\
\text { públicos que executam } \\
\text { suas atividades passiveis } \\
\text { de serem investigados por } \\
\text { crime; } \\
\text { Introduz regra que reprime } \\
\text { o exercício de competên- } \\
\text { cias constitucionalmente } \\
\text { atribuídas aos Tribunais } \\
\text { de Contas; } \\
\text { Esse dispositivo possibilita } \\
\text { que os julgadores dos } \\
\text { Tribunais de Contas pos- } \\
\text { sam ser considerados } \\
\text { sujeitos ativos do crime. }\end{array}$ \\
\hline 4.4.4 Possibili- & Não prevê a pos- & Cap. & & Desestimula a participa- \\
\hline
\end{tabular}




\begin{tabular}{|c|c|c|c|c|}
\hline Item/ Sub item & Lei no 8.666/93 & PL no 559/13 & Aspectos Positivos & Aspectos Negativos \\
\hline $\begin{array}{l}\text { dade de respon- } \\
\text { sabilizar o de- } \\
\text { nunciante de } \\
\text { irregularidade }\end{array}$ & $\begin{array}{l}\text { sibilidade de res- } \\
\text { ponsabilização } \\
\text { com relação às } \\
\text { denuncias } \\
\text { Cap. VI, art. 113, } \\
\S 1^{\circ}\end{array}$ & $\begin{array}{l}\text { seção IV, art. } \\
148 \text { e pará- } \\
\text { grafos } \S 1^{\circ} \text { a } \\
\S 2^{\circ}\end{array}$ & & $\begin{array}{l}\text { ção da sociedade e agen- } \\
\text { tes públicos no controle } \\
\text { social dos gastos públicos; } \\
\text { A redação proposta é uma } \\
\text { afronta a Constituição que } \\
\text { prevê e garante o direito a } \\
\text { denúncias de irregularida- } \\
\text { des ou ilegalidades. }\end{array}$ \\
\hline
\end{tabular}

O quadro acima contém o resumo de todas as alterações tratadas nesta pesquisa, e das alterações consideradas relevantes para as atividades do gestor Público. $\mathrm{Na}$ análise dos itens apresentados, percebe-se que algumas das mudanças propiciam benefícios às atividades do gestor, contudo a maioria demonstra que a atual redação traz pontos negativos, os quais trazem prejuízo às atividades do gestor e a atuação dos órgãos de controle e fiscalização, além de trazer mecanismos que propiciam a formação de conluios e fraudes nas licitações.

\section{Conclusão}

Selecionar a proposta mais vantajosa para a Administração Pública é um desafio para todos aqueles que lidam com processos licitatórios na esfera Federal, Estadual ou Municipal, principalmente para o gestor público o qual é o responsável pela tomada de decisões, devendo este zelar pela correta aplicação e pelo eficiente gerenciamento dos recursos públicos, na forma da lei. O processo de qualquer contratação, na qual estejam envolvidos recursos públicos deve ser conduzido com cautela, pois além do fato desses recursos pertencerem à sociedade, existem regras preestabelecidas com destaque para a Lei de Licitações- Lei o 8.666/93 (BRASIL, 1993), as quais devem ser obedecidas a fim de que seja selecionada a proposta mais vantajosa para a Administração Pública.

Diante das características próprias das licitações públicas, as quais possuem regras e procedimentos próprios que devem ser seguidos, os cuidados a serem adotados pelo gestor no gerenciamento e condução das licitações devem ser redobrados. O conhecimento da Lei de Licitações para o gestor é de suma importância para que ele desempenhe as suas atividades de forma a atender com qualidade, eficiência e celeridade. Nesse sentido, a tramitação do projeto de Lei - PL no 559/13 (BRASIL, 2013) que propõe a alteração da Lei de Licitações atual - Lei no 8.666/93 (BRASIL, 1993), através da sua revogação juntamente com a Lei o 10.520/02 (BRASIL, 2002) e Lei ํo 12.462/11 (BRASIL, 2011), deve ser acompanhada e avaliada pelo gestor público uma vez que modifica o regramento existente nas licitações públicas e nos procedimentos por ele conduzido.

É pertinente destacar que esse trabalho teve, também, o intuito de despertar a discussão necessária, além de tratar-se de um estudo introdutório que requer continuidade e aperfeiçoamento. Dessa forma, a partir da pesquisa realizada e das opiniões levantadas dos autores e entidades utilizados no trabalho, sugere-se evitar a revogação das atuais Leis, Lei de Licitações- Lei № 8.666 
(BRASIL, 2013) e Lei do Pregão- Lei no 10.520 (BRASIL, 2002), sem o devido amadurecimento e confiabilidade de que estas alterações suprem a necessidade existente, e das normas gerais vigentes sem que se tenha conhecimento da avaliação comparativa dos parâmetros mínimos para conferir maior segurança à tomada de decisão pelo parlamento brasileiro acerca de matéria extremamente complexa e que permeia todos os setores da gestão pública.

Dentre as apreensões com relação à nova redação, merece destaque a falta de trabalhos que consolidem de modo sistematizado os resultados de análises e fiscalizações, as quais possibilitem diagnosticar os pontos positivos e fatores críticos principalmente dos itens advindos do Regime Diferenciado de Contratação (RDC) (BRASIL, 2011), mais especificamente no que tange a contratação integrada, além dos impactos e consequências resultantes dos mecanismos que se pretende impor aos órgãos de controle e fiscalização, principalmente os Tribunais de Contas, os quais têm a intenção de coibir a atuação na gestão pública. Outro ponto a ser considerado são as inúmeras entidades de classe, representativas de diversos segmentos, as quais questionam e principalmente levantam à discussão aspectos negativos de diversos itens da nova redação e suas consequências danosas, relatadas em ofícios e manifestações técnicas encaminhas para apreciação da Comissão responsável pela tramitação do PL ํㅜ 559/13 (BRASIL, 2013).

A Lei de licitações deve, efetivamente, adequar-se e ser alterada quando, como e onde for necessário, a ser realizada através de um profundo estudo, com muita cautela e discussão entre diferentes entidades envolvidas. A mera substituição de uma norma por outra ou sua repetição, não conduz ao aperfeiçoamento tão almejado para as licitações públicas, devendo-se buscar com essa alteração a transformação em um instrumento permanente e não volátil ao sabor de interesses momentâneos. Diferentemente da Lei 8.666/93 (BRASIL, 1993), promulgada após um debate de dois anos no Congresso Nacional envolvendo os estudiosos e os conhecedores do assunto, o RDC (BRASIL, 2011) foi aprovado sem a contribuição e participação dos estudiosos, dos entendidos na matéria e, principalmente, das entidades que mais conhecem os sorrateiros mecanismos utilizados por aqueles que desejam poder conduzir as licitações e, assim, direcionar os contratos conforme a sua vontade pessoal. Dessa forma o RDC (BRASIL, 2011) e os mecanismos advindos dela e inseridos na redação do PL o 559/13 (BRASIL, 2013) podem impor profundas e ruinosas mutilações em vários princípios essenciais da Lei de Licitações (BRASIL, 1993), reintroduzindo e ampliando mecanismos que permitiam o direcionamento espúrio das licitações.

Dentre as críticas que existem em relação à Lei no 8.666/93 (BRASIL, 1993) pode-se destacar a de ser considerada muito burocrática, criando excessivas regras e retardando as contratações, além de não haver um destaque muito claro para a fase de planejamento. Contudo, não se pode considerar a atual lei como única responsável, nem creditar a ela todos os problemas existentes nas licitações, ao contrário, a ausência de planejamento e qualificação da Administração Pública e de seus gestores é um dos maiores causadores de atrasos e de contratações desastrosas, deixando para trás obras não concluídas em deterioração ou malfeitas, além de desperdiçar dinheiro público tão necessário em várias outras áreas, e de dificultar a investigação dos gastos realizados e a verificação da qualidade dos serviços executados. 
A ausência de planejamento é um dos principais fatores que prejudicam as licitações, a realidade mostra que a legislação atual não possui elementos suficientes para incentivar e exigir maior planejamento dos gestores públicos e da Administração Pública. Um exemplo disso foi a ineficiência, falta de planejamento e de mecanismos legais de controle, através das contratações via RDC (BRASIL, 2011) na Copa do Mundo, a qual além de prejudicial ao erário público resultou em obras atrasadas ou inacabadas, desperdício de recursos e incalculáveis prejuízos à população e à imagem do país. A solução que poderia vir com o Projeto de Lei no 559/13 (BRASIL, 2013), na questão do planejamento das contratações públicas, não foi contemplado e ainda prevê uma série de retrocessos, como impedir que o Tribunal de Contas atue a qualquer momento mesmo que haja indícios de legalidade, desestimular as denúncias de irregularidades feitas pela sociedade ao prever penalização. Além de ser maior, com 50 artigos a mais, e possuir texto mais confuso que a atual Lei no 8.666/93 (BRASIL, 1993).

Sendo assim, a presente pesquisa não impede, mas ao contrário sugere que futuramente sejam lançados outros apontamentos em relação ao texto do Projeto de Lei, inclusive porque, numa análise mais profunda, visualizam-se inúmeros outros dispositivos passíveis de questionamento e comparação à atual Lei de Licitações. Necessitando de outros estudos e comparativos para verificar todos os benefícios ou desvantagens, necessidades levantadas e mecanismos de controle que deveriam estar presentes na nova redação, conjuntamente com os apontamentos importantes das entidades de classe envolvidas, além da exclusão de itens que sejam considerados danosos aos interesses públicos. Incluem-se nesses novos estudos, a proposta de futuro trabalho mais abrangente que $o$ atual, o qual foi limitado pelos fatores citados anteriormente, principalmente com relação aos itens contratação integrada e restrição à atuação dos órgãos de controle e fiscalização- Tribunais de Conta. Os quais foram os itens considerados mais criticados e discutidos, demonstrando a relevância e importância de novo estudo mais aprofundado e que considere novas análises e discussões, para que possa proporcionar ao gestor público uma visão mais abrangente e completa.

\section{Referências}

BRASIL. Constituição Federal de 1988. Disponível em: $<$ Http://www.planalto.gov.br/ccivil_03/constituicao/constituicaocompilado.htm>. Acesso em 14 set. 2015.

Decreto no 5.450, de 31 de maio de 2005. Regulamenta o pregão, na forma eletrônica [...]. Disponível em:<http://www.planalto.gov.br/ccivil_03/_ato2004-2006/2005/decreto/d5450.htm>. Acesso em 14 set. 2015.

Lei no 8.666 de 21 de junho de 1993. Regulamenta o art. 37, inciso XXI, da Constituição Federal institui normas para licitações [...]. Disponível em:< http://www2.camara.leg.br/legin/fed/lei/1993/lei-8666-21-junho-1993-322221-normaatualizada-pl.pdf>. Acesso em: 14 set. 2015.

Lei no 10.520, de 17 de julho de 2002. Institui, no âmbito da União, Estados, Distrito Fede$\overline{\text { ral e }}$ Municípios, nos termos do art. 37 [...]. Disponível em:< http://www.planalto.gov.br/ccivil_03/leis/2002/L10520.htm>. Acesso em 19 out. 2015. 
Lei no 12.462, de 4 de agosto de 2011. Institui o Regime Diferenciado de Contratações Públicas - RDC [...]. Disponível em:< http://www.planalto.gov.br/ccivil_03/_ato20112014/2011/Lei/L12462.htm>. Acesso em 19 out. 2015.

Projeto de Lei da Câmara no 32 de 2007. Institui o Código de Licitações e Contratos da Administração $\quad$ Pública $\quad[. .$.$] Disponível \quad$ em:< http://www.camara.gov.br/proposicoesWeb/prop_mostrarintegra?codteor=433783\&filename=PL+32/2 007>. Acesso em 19 out. 2015.

Projeto de Lei do Executivo no 7.709 de 2007. Altera dispositivos da Lei no 8.666, de 21 de junho de $1993 \quad$ [...]. $\quad$ Disponível $\quad$ em:< http://www.camara.gov.br/proposicoesWeb/prop_mostrarintegra;jsessionid=808F65527DE5B8317840 5F980AC27385. proposicoesWeb2 ?codteor $=433303 \&$ filename $=P L+7709 / 2007>$. Acesso em 19 out. 2015.

Projeto de Lei do Senado no 559 de 2013. Institui normas para licitações e contratos [...]. Disponível em:< http://www.senado.leg.br/atividade/rotinas/materia/getPDF.asp?t=143724\&tp=1>. Acesso em: 14 set. 2015.

Projeto de Lei Câmara dos Deputados no 6814 de 2017. Institui normas para licitações e contratos [...]. Disponível em:< http://www.camara.gov.br/proposicoesWeb/fichadetramitacao?idProposicao=2122766>. Acesso em: 27 nov. 2017.

BICALHO, A. P. N. Recentes alterações e perspectivas do Regime Diferenciado de Contratações nas Obras e serviços de engenharia. Fórum de Contratação e Gestão Pública - FCGP, Belo Horizonte, ano 13, n. 153, p. 9-20, 2014.

FIUZA, E. P. S.; MEDEIROS, B. A. A agenda perdida das compras públicas: rumo a uma reforma abrangente da lei de licitações e do arcabouço institucional. Texto para discussão. Instituto de Pesquisa Econômica Aplicada- IPEA. Rio de Janeiro: 1990, 2014.

SPRICIGO, P. R.; FONSECA, S. A. Inovações nos Procedimentos para Compras e Contratações na Administração Pública: Breve Avaliação das Contribuições do Pregão. Temas de Administração Pública. v.2, n.3, 2008. 